\title{
Offshore wind turbine fatigue loads: The influence of alternative wave modeling for different turbulent and mean winds
}

\author{
Enzo Marino ${ }^{\text {a, }}, 1$, , Alessandro Giusti ${ }^{\text {a }}$, Lance Manuel ${ }^{\text {b }}$ \\ ${ }^{a}$ Dept. of Civil and Environmental Engineering, University of Florence, Italy \\ b Dept. of Civil, Architectural, and Environmental Engineering, The University of Texas at Austin, USA
}

\section{A R T I C L E I N F O}

Article history:

Received 29 February 2016

Received in revised form

1 August 2016

Accepted 13 October 2016

Available online 17 October 2016

Keywords:

Offshore wind turbines

Fatigue loads

Nonlinear waves

\begin{abstract}
A B S T R A C T
The coupled hydro-aero-elastic response and fatigue loads of a bottom-supported offshore wind turbine under different wind conditions and for different wave modeling assumptions is the subject of this study. Nonlinear modeling of hydrodynamic forcing can bring about resonant vibrations of the tower leading to significant stress amplitude cycles. A comparison between linear and fully nonlinear wave models is presented, with consideration for different accompanying mean wind speeds and turbulence intensities. Hydrodynamic and aerodynamic loads acting on the support structure and on the rotor of a 5-MW wind turbine are modeled in a fully coupled hydro-aero-elastic solver. A key finding is that when the turbine is in a parked state, the widely used linear wave modeling approach significantly underestimates fatigue loads. On the other hand, when the wind turbine is in power production, aerodynamic loads are dominant and the effects due to consideration of nonlinear wave kinematics become less important.
\end{abstract}

๑) 2016 Elsevier Ltd. All rights reserved.

\section{Introduction}

A sustained demand for renewable energy over time has resulted in an increased need for greater investment in offshore wind energy generation and possibly larger turbines. The increasing sensitivity of taller towers and lighter, more flexible blades to the coupled wind-wave dynamic excitation requires more careful numerical modeling to guarantee safe and economic designs. In an earlier study, Marino et al. [1] introduced an efficient computational scheme based on a domain decomposition strategy that is able to accurately describe nonlinear hydrodynamic loads exerted on offshore wind turbines exposed to severe environmental conditions. In contrast to more complex domain decomposition methods, e.g., Paulsen et al. [2], the numerical model in Marino et al. [1] is based purely on potential flow theory and permits representation of any degree of nonlinearity, even up to the extreme case of breaking waves [3-5]. It was also shown [6] that consideration of nonlinear wave kinematics in the study of wind turbine extreme loads has different influences depending on the operational state of the turbine. It was demonstrated that in a parked state, resonant vibrations at the fundamental frequency of

\footnotetext{
* Corresponding author. Via di Santa Marta, 3, 50139 Firenze, Italy. E-mail address: enzo.marino@dicea.unifi.it (E. Marino).

1 http://people.dicea.unifi.it/emarino/.
}

the tower are induced by the interaction of the structure with steep waves [7]; these phenomena, however, are suppressed by aerodynamic damping when the turbine is in a power-production state. Resonant hydro-elastic response associated with both nonbreaking and breaking nonlinear waves may interact with the rotor dynamics as well [8]. These various previous studies have led to a few key findings: in severe sea states, the structural response of a monopile-supported offshore wind turbine is greatly underestimated when linear wave theory is assumed and, more importantly, dangerous resonance conditions, such as ringing events following large and steep waves [9-11], can be captured only when high-order nonlinear wave contributions are accounted for [1,6-8]. Weakly nonlinear wave models, e.g., second-order waves, can lead to higher design loads than are obtained with linear wave models $[12,13]$; however, as shown elsewhere [14,15], they are often unable to accurately describe higher-order resonant ringing-like behavior.

The fatigue damage that a turbine tower accumulates depends directly on the number and amplitude of stress cycles experienced during its life. Therefore, both the amplification and the increase in number of tower load cycles, such as those that accompany resonance-like conditions triggered by nonlinear wave hydrodynamics discussed above, will affect the assessment of the fatigue damage [16].

There are only a limited number of studies to date that specifically address the influence of wave modeling on fatigue loads. 
Veldkamp and van der Tempel [17] investigated the sensitivity of fatigue loads for a monopile-supported offshore wind turbine to three factors: (i) the shape of the wave spectrum; (ii) assumed wave kinematics models arising from first-order, second-order and nonlinear theories; and (iii) inertia and drag coefficients used with Morison's equation. The main conclusions from that study were that, for the selected site-specific data set, the JONSWAP spectrum provided an acceptable representation of the actual wave conditions at least for loads associated with the dominant (first-order) wave frequency. With regard to the calibration of the inertial term in Morison's equation, the authors concluded that a value of 2 appeared to be the best choice for the Keulegan-Carpenter (KC) number considered. While on (i) and (ii), Veldkamp and van der Tempel [17] provided qualitative and quantitative results, on (ii) actual fatigue loads associated with the different wave models were not computed. In Ref. [18], an irregular second-order wave model was employed to simulate the dynamic response of a monopilesupported wind turbine located at a site with a water depth of $25 \mathrm{~m}$. The authors showed that fatigue loads were about $7.5 \%$ greater than with linear wave models and they also pointed out that fatigue damage with second-order waves was even more greatly enhanced when the waves were orthogonal to the wind; this emphasizes the role of wind-wave misalignment. They attributed this greater influence of nonlinear wave modeling to the fact that reduced aerodynamic damping from the rotor results when wind and waves are not aligned. We concur with this finding and with similar observations made elsewhere $[1,6,8,16,19,20]$; the absence of aerodynamic damping also seen in the parked state of the rotor has the same effect, namely, greater sensitivity of turbine loads to nonlinear wave modeling assumptions.

Additional studies related to fatigue loads on offshore wind turbines supported by monopiles, tripods or jacket platforms have been presented in a number of papers. These studies employed time-domain as well as frequency-domain methods (see Refs. [21,22] for a comparison of the use of the two methods) to calculate fatigue loads. The performance of different spectral models and guidance to their selection was discussed in Ref. [23]. A more efficient time-domain approach was presented in Ref. [24]. Probabilistic fatigue analysis and reliability-based approaches have been discussed in Refs. [25-28]. In Ref. [29], a new method that considers wind-wave correlation for the determination of fatigue design loads was proposed. The effect of wind directionality was investigated in Ref. [30]. In Refs. [31,32], the variability in site conditions and their influence on fatigue loads in turbines sited in large wind farms was studied. Fatigue loads as a function of atmospheric stability were studied in Ref. [33]. Corrosion-related fatigue for offshore wind turbines was addressed in Refs. [27,34,35].

There is only one study available in the literature performed in 2012 by Schløer et al. [36] which specifically addressed the effects of fully nonlinear waves on the fatigue life of an offshore wind turbine. The same monopile-supported wind turbine analyzed in the present paper was investigated with a water depth of $40 \mathrm{~m}$. Five representative sea states with different significant wave heights were considered and two wind-wave combinations were used in the aeroelastic computations: the first involved a steady uniform wind with low wind speed maintained the same for all five sea states, while the second involved turbulent wind and a wind speed consistent with the changing significant wave height in the five sea states. The main conclusion was that both ringing-like excitations and equivalent fatigue damage caused by the nonlinear wave forcing were only significant at low wind speeds when the aerodynamic damping is low.

Based on the brief literature review summarized above, it appears that the selection of alternative wave kinematics models has been investigated in a rather limited number of prior studies, where at most weakly nonlinear models have been considered. Fully nonlinear waves have been employed only in Refs. [36] and [16]. There is a noted lack of investigations aimed at assessing the sensitivity of fatigue loads to fully nonlinear wave models and on how this sensitivity varies when understood in combination with different wind conditions. Motivated by the important results presented in Refs. $[6,16,36]$, the objective of the present work is to perform a more comprehensive comparative study of fatigue loads using linear (L) and fully nonlinear (FNL) wave models and to investigate the sensitivity of the estimated fatigue loads to different mean wind speeds and turbulence intensity levels. In order to gain a deeper understanding of the role of aerodynamic damping in the assessment of fatigue loads, both parked and power-production turbine states as well as some reference base conditions, such as the wind-only and wave-only loading cases plus one with blade degrees of freedom suppressed are considered.

The paper is organized as follows. In Section 2, we briefly review the main features of the global solver and then describe the wind and wave loading models as well as the methodology used for the fatigue damage assessment. In Section 3, results in the time and frequency domains are discussed for both parked and powerproduction turbine states. Finally, in Section 4, we draw the main conclusions of the present study.

\section{Methodology}

The overall computational framework is based on a coupling between the aero-servo-elastic software FAST [37] with a hydrodynamics module developed in Refs. [1,3]. The global solver is based on a combined modal and multibody dynamics formulation to model the rigid and flexible bodies comprising the complete system. Flexible beam elements, suitably described in terms of generalized coordinates and a linear modal representation (assuming small deflections), are used to describe the two flapwise bending modes and one edgewise bending mode for each blade and the two fore-aft and two side-side bending modes for the tower.

\subsection{Wind model}

Full-field three-component turbulent wind fields are generated by means of the NREL software, TurbSim [38]. A normal turbulence model (NTM) is assumed, as defined in the IEC 61400-1 standard [39]. All the three turbulence categories, A, B, and C (with reference turbulence intensity levels of $0.16,0.14$ and 0.12 , respectively) are considered. Kaimal power spectra and an exponential coherence model for longitudinal turbulence are employed to describe the inflow velocity field over the rotor plane. A computational grid vertical plane covering an area equal to $140 \times 140$ square meters with $15 \times 15$ points centered at the turbine hub is used. This domain and grid resolution allow an optimal compromise between accuracy and computational effort [40]. The mean wind profile is specified using a power-law format with a wind shear exponent of 0.2 . Wind forces are calculated using AeroDyn, which is based on the Blade Element Momentum (BEM) theory [41,42].

\subsection{Nonlinear wave model}

To save computational time, the wave kinematics model is based on the domain-decomposition strategy proposed in Ref. [1]. According to this model, the fully nonlinear (FNL) governing equations representing the gravity waves are solved only on special subdomains where nonlinearities arise.

Once a significant wave height and peak spectral period are assigned for a specific sea state, an irregular sea is first generated in the time domain using a Fourier-based spectral approach. A zero- 
crossing analysis of the sea surface elevation at the wind turbine location permits identification of those time instants at which nonlinear waves are expected. Such time instants are estimated under the linear wave theory assumption - namely, first the wave periods and wave heights are extracted from the wave elevation time series, then the dispersion relation enables computation of wave numbers and wavelengths corresponding to the detected wave periods. The local steepness of each wave component can be computed and compared with a critical threshold. The time instant at which such a critical steepness is exceeded (see Eq. (1) of [1]) represents the temporal center of the sub-domain. Each of these identified time instants, along with the spatial location of the wind turbine, defines a time-space sub-domain on which the FNL governing equations are solved. Potential flow theory is assumed and the resulting Laplace equation with associated nonlinear freesurface boundary conditions is solved by means of a second-order boundary element method. Time-step integration is performed by means of a 4th-order Runge-Kutta scheme. The free-surface timedependent potential problem is solved by means of a two-step mixed Eulerian-Lagrangian scheme.

At the end sections of the spatial sub-domains, linear wave theory for the wave kinematics is used to enforce boundary conditions for the FNL solver; similarly, for each temporal sub-domain, linear wave kinematics are used to initialize the numerical solver. The transition from the linear to the nonlinear solution (and vice versa) is handled with ramp functions and plays a crucial role in the accuracy of the proposed computational scheme. To ensure that the nonlinear evolution of the wave field is correct and representative of a steep irregular wave, several studies have been performed in previous works and are briefly recalled here. In Ref. [1], the tuning of the ramp function parameters was performed by comparing the numerical solution with the exact Stokes solution for the regular wave case. Additional tests performed in Refs. [1,6] consisted in comparing the solution obtained with the proposed domain decomposition scheme with that obtained without any domain decomposition - that is, the numerical solution is used over the whole space-time domain. By assuming the latter as a reference solution, results showed that the domain-decomposition solution was able to predict the reference solution with an error of $1.1 \%$, while saving $88.5 \%$ of the computational time. We refer to earlier studies $[1,3,6]$ and references therein for a comprehensive description and validation of the numerical wave solver.

Long-crested irregular waves are generated using the JONSWAP spectrum and hydrodynamic forces for the selected monopilesupported 5-MW turbine are calculated using Morison's equation [43]. When linear kinematics is used, the solution at the free surface is obtained using constant stretching, which means that the same kinematics at $z=0$ are assumed to apply up to the free surface.

\subsection{Fatigue load assessment}

We compute fatigue damage for each simulated load time series using the well-known Miner's rule and S-N curves for damage accumulation [16,21]. The Wöhler exponent is taken to be 3 (for the turbine tower welded steel). Estimations of damage depend on simulated variable-amplitude load cycles and are carried out in the
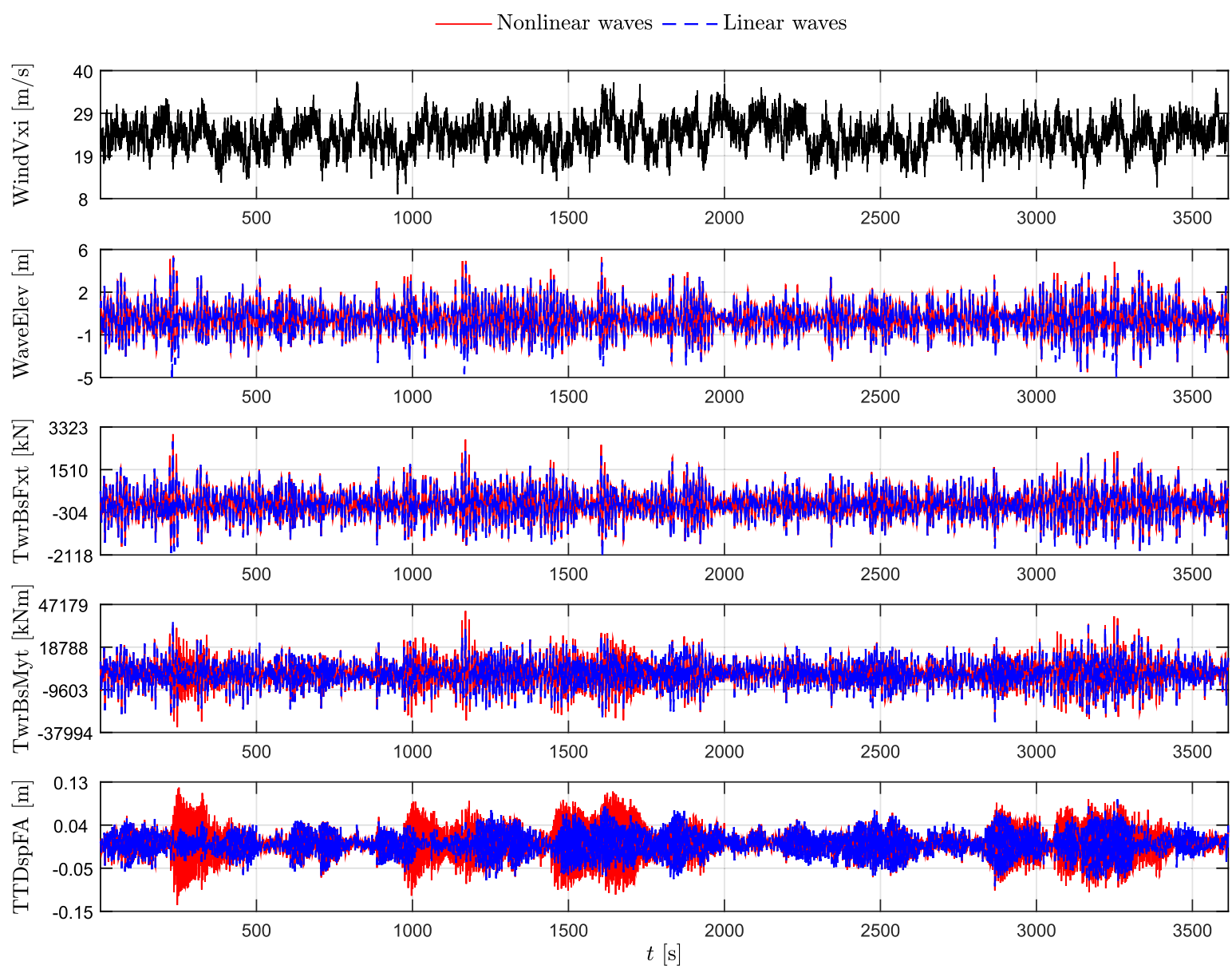

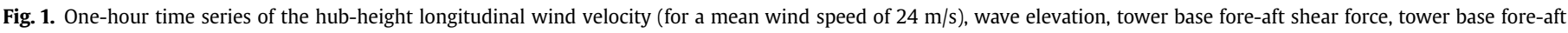
bending moment, and tower-top fore-aft deflection. Linear (dashed line) and nonlinear (solid line) responses are compared. The turbine is in a parked state. 
time domain using Rainflow Cycle-Counting (RCC). We use the concept of a "damage-equivalent load" (DEL) defined as the constant-amplitude stress range which, over a fixed number of cycles $N^{*}$ (the same for all the time series to be compared), causes the same amount of damage as the original variable-amplitude stress time series. The DEL is related to the actual damage, $D$, such that $\mathrm{DEL}^{m} N^{*}=D$; in all the simulations, we used $N^{*}=1000$. Effectively, our choice of $N^{*}$ suggests that DEL will represent the constant amplitude of 3.6-sec load cycles (or $0.28-\mathrm{Hz}$ load cycles).

The total damage due to an irregular loading is calculated by simply adding up the increments in damage due to each stress cycle; this can then be used in a total life calculation. No memory or sequence effects are considered (i.e., the increment in damage manifested, say, in crack growth depends only on the current applied stress range and crack dimensions, and not on past loading). This is an approximation but Miner's rule is customarily used for wind turbine fatigue loads evaluation when simulation is involved. The application of more advanced damage accumulation theories capable of accounting for the continuous deterioration of material properties under cyclic loading is postponed to future studies.

\subsection{The FINO site environmental conditions}

Probability distributions for parameters related to the wind and wave environment are based on data from the research platform Forschungplattformen in Nord-und Ostsee (FINO) [44]. The selected platform is located in the German Bight at $54^{\circ} 0.86^{\prime} \mathrm{N}, 6^{\circ}$ $35.26^{\prime} \mathrm{S}$, about $45 \mathrm{~km}$ north of the Island of Borkum in the North
Sea.

The 10-min hub-height wind speed is given by a Weibull distribution as follows:

$F(u)=P(U<u)=1-\exp \left[-\left(\frac{u}{a}\right)^{c}\right]$

where $a=11.789 \mathrm{~m} / \mathrm{s}$ and $c=2.310$. This mean wind speed distribution is used for time-domain simulations of full wind velocity fields over a duration of $1 \mathrm{~h}$. The significant wave height and zerocrossing wave period, for the simulations, are taken at their conditional expected values, given $U$.

The 1-h significant wave height, $H_{s}$, conditional on $U$, is given by a Weibull distribution as follows:

$F(H \mid u)=P\left(H_{s}<h \mid U=u\right)=1-\exp \left[-\left(\frac{h}{a_{h}(u)}\right)^{c_{h}(u)}\right]$

where $a_{h}(u)=0.7704+0.01304 u^{1.7696} \quad$ (in meters) and $c_{h}(u)=1.535+0.01304 u$.

Additional details related to the conditional expected values of the significant wave height and spectral period (given $U$ ) are given in Refs. [7,20].

\subsection{The 5-MW wind turbine reference model}

In this study, the NREL 5-MW baseline wind turbine model [45] is used for all the simulations. This model was originally developed to support concept studies aimed at the evaluation of various

Nonlinear waves - - - Linear waves
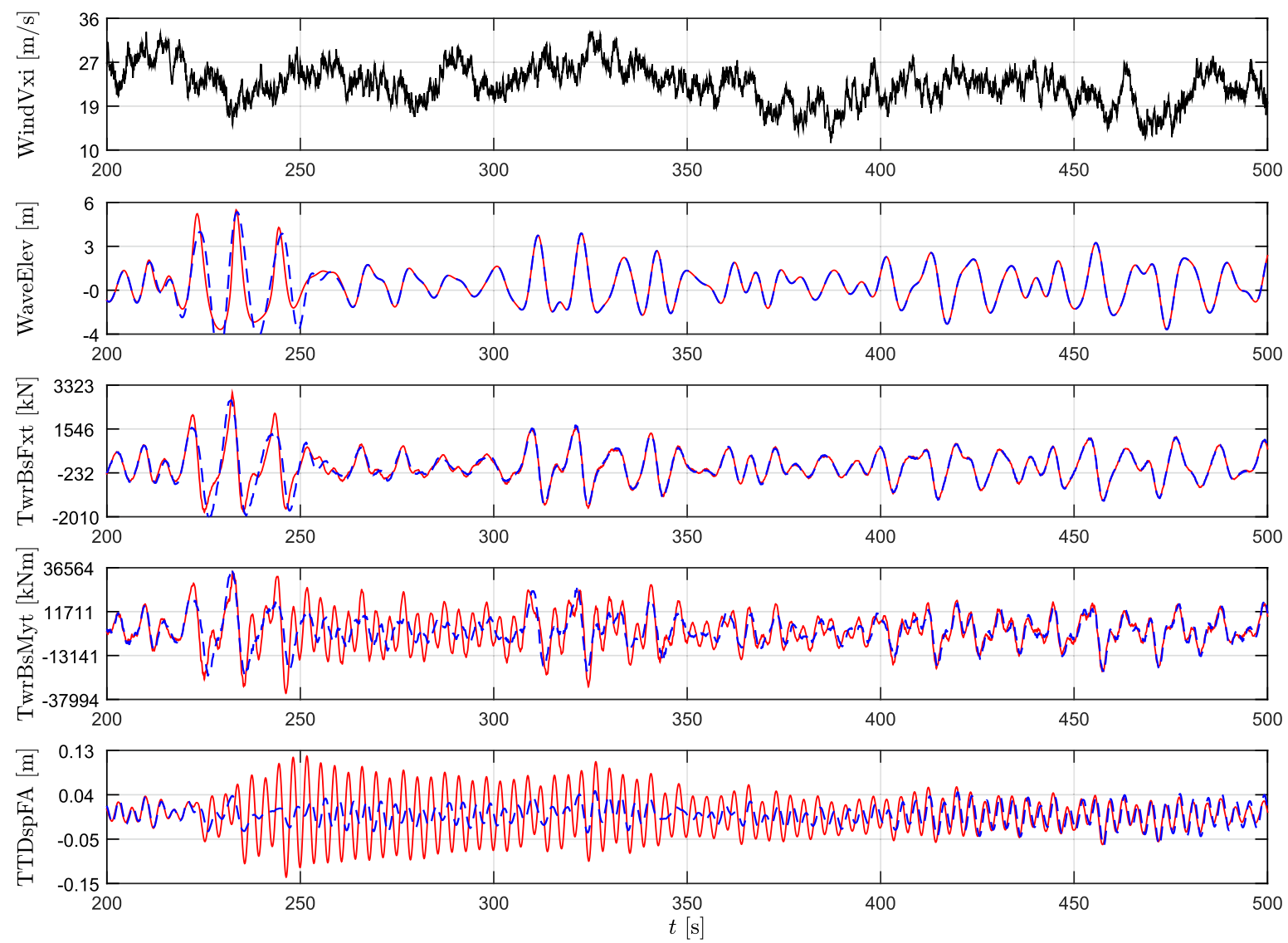

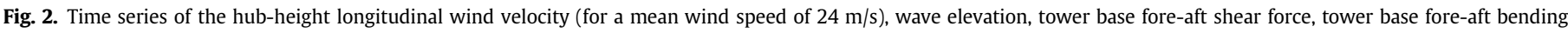
moment, and tower-top fore-aft deflection. Linear (dashed line) and nonlinear (solid line) responses are compared. The turbine is in a parked state. Close-up of event 1. 
offshore wind turbine designs. The turbine is a variable-speed, collective pitch-controlled machine with a rated rotor speed of $12.1 \mathrm{rpm}$; its rated wind speed is $11.4 \mathrm{~m} / \mathrm{s}$. It has a hub height of $90 \mathrm{~m}$ above the mean sea level, and a rotor diameter of $126 \mathrm{~m}$. It is assumed to be sited in $20 \mathrm{~m}$ of water; it has a monopile support structure of $6 \mathrm{~m}$ diameter, which is assumed to be rigidly connected to the seabed.

\section{Time-domain simulations and results}

In this set of numerical results, we focus on the effects that different wind conditions, represented by different mean wind speeds and turbulence intensity levels, have in terms of system response and fatigue loads when linear or nonlinear wave models are employed. We discuss results for a case where the turbine is in a parked state, with the rotor idling and the three blades fully pitched to minimize aerodynamic loads, as well as the results obtained when the wind turbine is in power production. We consider cases where the wave conditions are kept the same, while the wind speed and turbulence intensity levels are changed. The wave conditions are characterized by a significant wave height, $H_{s}$, equal to $5.60 \mathrm{~m}$ and a wave spectral peak period, $T_{p}$, equal to $10.82 \mathrm{~s}$, which are the conditional mean values of $H_{s}$ and $T_{p}$, for a hub-height wind speed, $U$, of $33.43 \mathrm{~m} / \mathrm{s}$, which is above the cut-out wind speed.
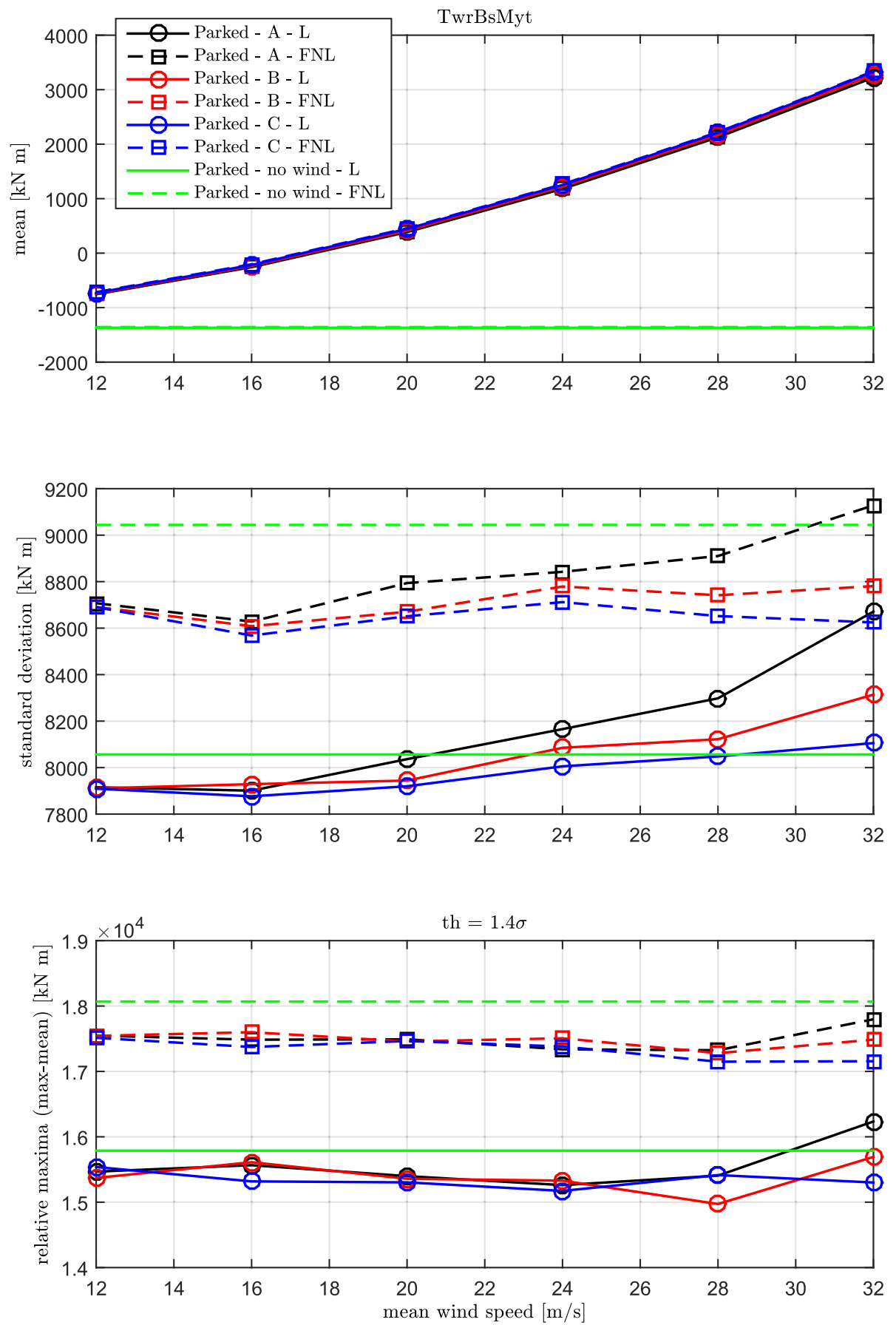

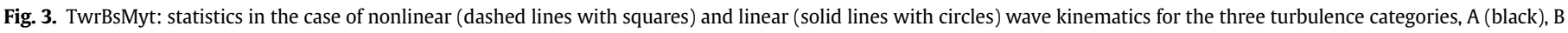
(red), C (blue). The turbine is in a parked state. (For interpretation of the references to colour in this figure legend, the reader is referred to the web version of this article.) 


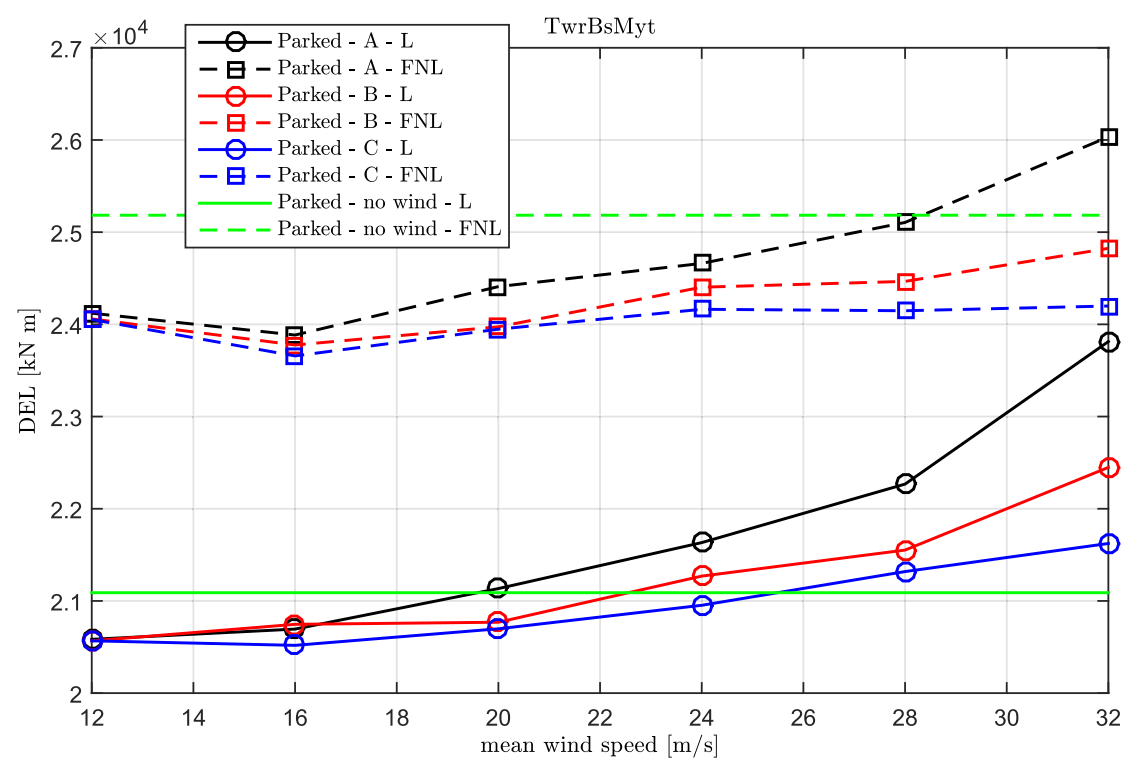

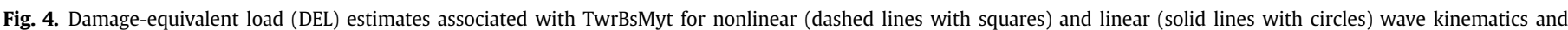

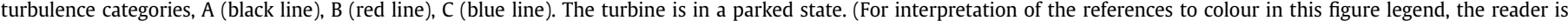
referred to the web version of this article.)

\subsection{Parked state}

We consider mean wind speeds from $12 \mathrm{~m} / \mathrm{s}$ to $32 \mathrm{~m} / \mathrm{s}$ in increments of $4 \mathrm{~m} / \mathrm{s}$. For each mean wind speed, three IEC turbulence categories - A, B, and C - are considered. Both linear (L) and fully nonlinear (FNL) wave models are considered for each wind condition. Thus, a total of 36 simulations are considered. Although wind speeds below $33.43 \mathrm{~m} / \mathrm{s}$ in combination with the selected wave conditions are not very likely to occur, we evaluate all these cases only because we are interested in understanding differences stemming from the $\mathrm{L}$ and $\mathrm{FNL}$ wave modeling on fatigue loads for all wind speeds. In order to make the results easier to interpret, even for wind speeds below cut-out, we assume that the turbine is parked in this first set of simulations. Later, we consider the turbine in an operating state.

\subsubsection{Analysis of the response time series}

Fig. 1 shows 1-h time series of the hub-height longitudinal wind velocity WindVxi for turbulence category $A$ and a hub-height mean wind speed of $24 \mathrm{~m} / \mathrm{s}$; the wave elevation WaveElev (considering $\mathrm{L}$ and FNL waves); and associated turbine tower loads (TwrBsFxt tower-base fore-aft shear force, TwrBsMyt - tower-base fore-aft overturning moment) and deflections (TTDspFA - tower-top foreaft displacements). Loads TwrBsFxt and TwrBsMyt are computed at the monopile base, which is the tower section at the mudline. The monopile is assumed in this study to be rigidly connected at the mudline. Because our focus is on wave modeling, we do not evaluate the bending moment at the bottom of the seabed within the soil; this would require a flexible foundation model such as has been the subject of other studies [46,47]. According to the wave screening criterion [1], 14 nonlinear events were detected; they occur at $[244 ; 560 ; 884 ; 1004 ; 1171 ; 1443 ; 1606 ; 1871 ; 2233 ; 2865$; $3085 ; 3250 ; 3401 ; 3537] \mathrm{s}$.

During event 1 (shown in Fig. 2), which is the only one discussed here in detail, the first significant nonlinear wave is observed at approximatively $222.5 \mathrm{~s}$ (within the radius of the temporal subdomain centered at $244 \mathrm{~s}$ ). The passage of this steep wave generates higher-order loading components (absent in the linear wave modeling) that trigger resonant vibrations of the tower. It is noted that, with the passing of this wave, the tower is seen to oscillate at its fundamental frequency of $0.28 \mathrm{~Hz}$ (see the TTDspFA time series in the bottom panel of Fig. 2). The excitation due to the nonlinear waves is persistent and it is only around $400 \mathrm{~s}$ that the response damps out and returns to similar levels as that predicted by the linear wave model. The enhanced response of the tower triggered by the nonlinear wave contributions is also reflected in the TwrBsMyt time series, where significantly higher response peaks compared to the linear wave case are observed. Similar behavior as in this event is observed in other sub-domains not reported here.

\subsubsection{Response statistics and fatigue loads}

Statistics of the tower-base fore-aft bending moment (TwrBsMyt) are presented in Fig. 3. As expected, the mean response (top panel) grows monotonically with mean wind speed. No significant differences in mean response are observed with the different turbulence categories or between the linear and nonlinear wave kinematics modeling choices. In contrast, the response standard deviation (s.d.), see the middle panel of Fig. 3, is about 10\% larger with the fully nonlinear (FNL) wave kinematics compared to the linear (L) wave kinematics. In both cases, the s.d. values increase slightly with increasing mean wind speed. The highest turbulence intensity (category A) brings about a somewhat larger increase in s.d. at higher mean wind speeds. In general, we observe that the response s.d. is sensitive to both wind speed and to wave modeling choice, with nonlinear waves leading to significantly higher s.d. response levels than linear waves.

The 1-h maximum loads (Fig. 3, bottom panel), computed as the mean value of the peaks over a selected threshold (equal to 1.4 s.d.), are up to $15 \%$ larger in the case with FNL wave kinematics compared to the $\mathrm{L}$ wave kinematics case. Since no differences were noted in the mean response between the $\mathrm{L}$ and FNL wave modeling choices, the difference in the maximum values is fully ascribed to fluctuations in the response - including s.d. effects and increasing nonlinearities and non-Gaussian characteristics - that result from the nonlinear wave modeling. Finally, we note that turbulence has only a small effect on the maximum values.

Fig. 4 shows DEL estimates associated with the tower-base foreaft bending moment TwrBsMyt. The FNL wave kinematics model 

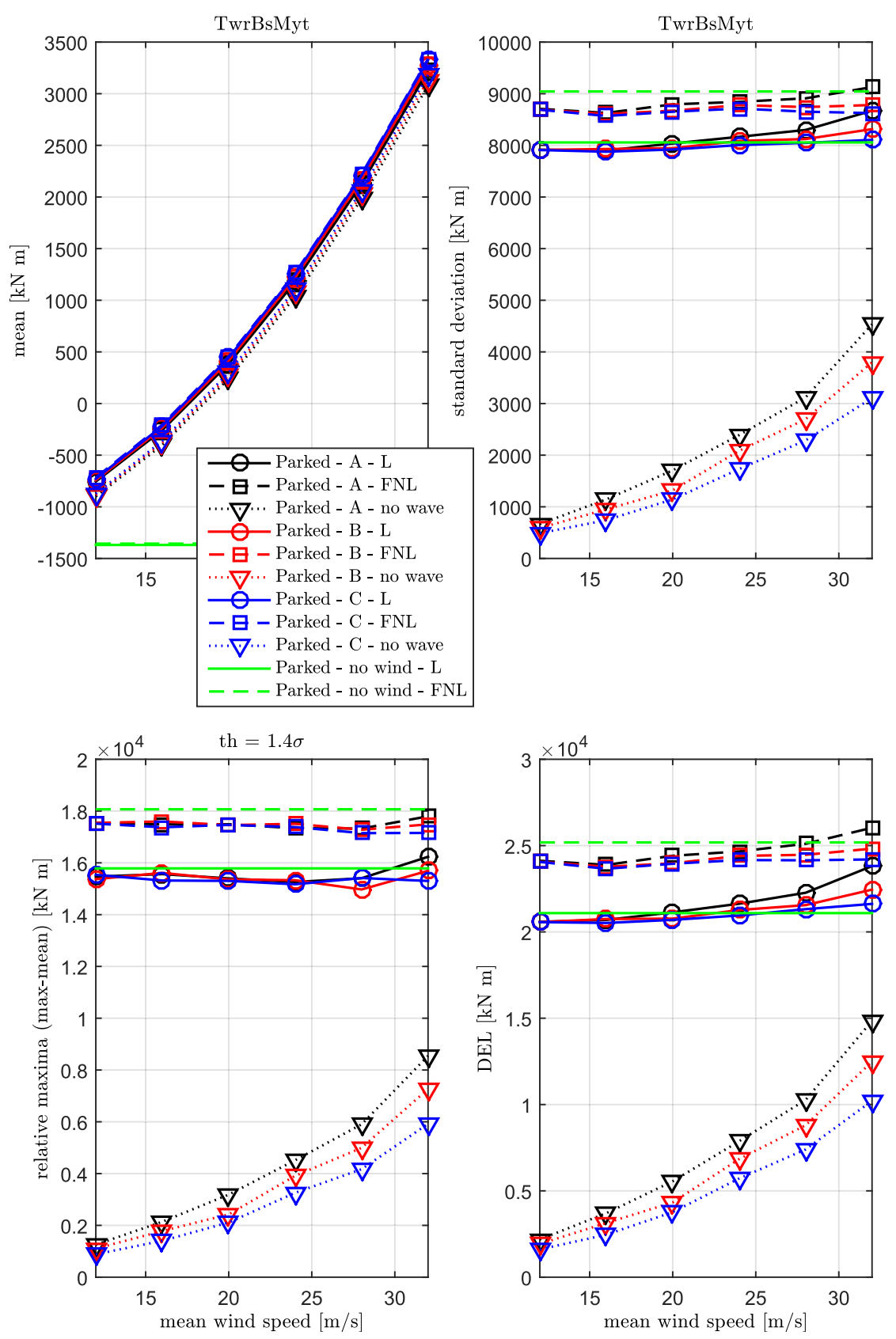

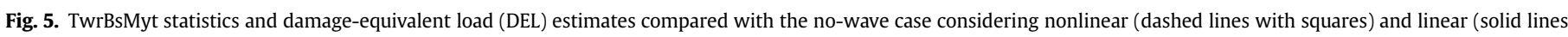

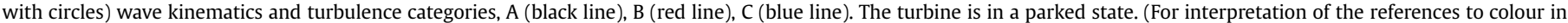
this figure legend, the reader is referred to the web version of this article.)

leads to significantly greater fatigue damage compared to what results from use of the linear wave model. At low wind speeds, the FNL wave model leads to $17 \%$ higher DEL; at higher wind speeds, these estimate are about 10\% higher. At higher turbulence levels, as expected, higher DEL estimates result. We note that DEL estimates follow the same trend with wind speed as was the case for the s.d. response reported in Fig. 3 (middle panel).

Figs. 3 and 4 include results for the reference base case with waves alone. We see that the aeroelastic interaction of the rotor blades caused by the presence of turbulent wind, although the turbine is in a parked state, introduces some damping. In fact, the response to the FNL waves with no wind is greater than when turbulent wind is considered. When the mean wind speed becomes high (say greater than $24 \mathrm{~m} / \mathrm{s}$ ), the aeroelastic damping is no longer large enough to prevent an increase in both the system response and the DEL. Basically, turbulent wind has two contrasting effects: it generates aeroelastic damping and it also increases excitation of the system.

Fig. 5 presents comparisons with the wind-only case. Some important facts may be noted. First, the mean response is influenced only and directly by the wind since the wave loading process has a mean value close to zero (except for small contributions due to the nonlinearities). For this reason, in the top-left panel of Fig. 5, the wind + wave case is very similar to the wind-only case; second, for the TwrBsMyt standard deviation (s.d.), maximum value (max) and DEL (see top-right, bottom-left, and bottom-right panels of 

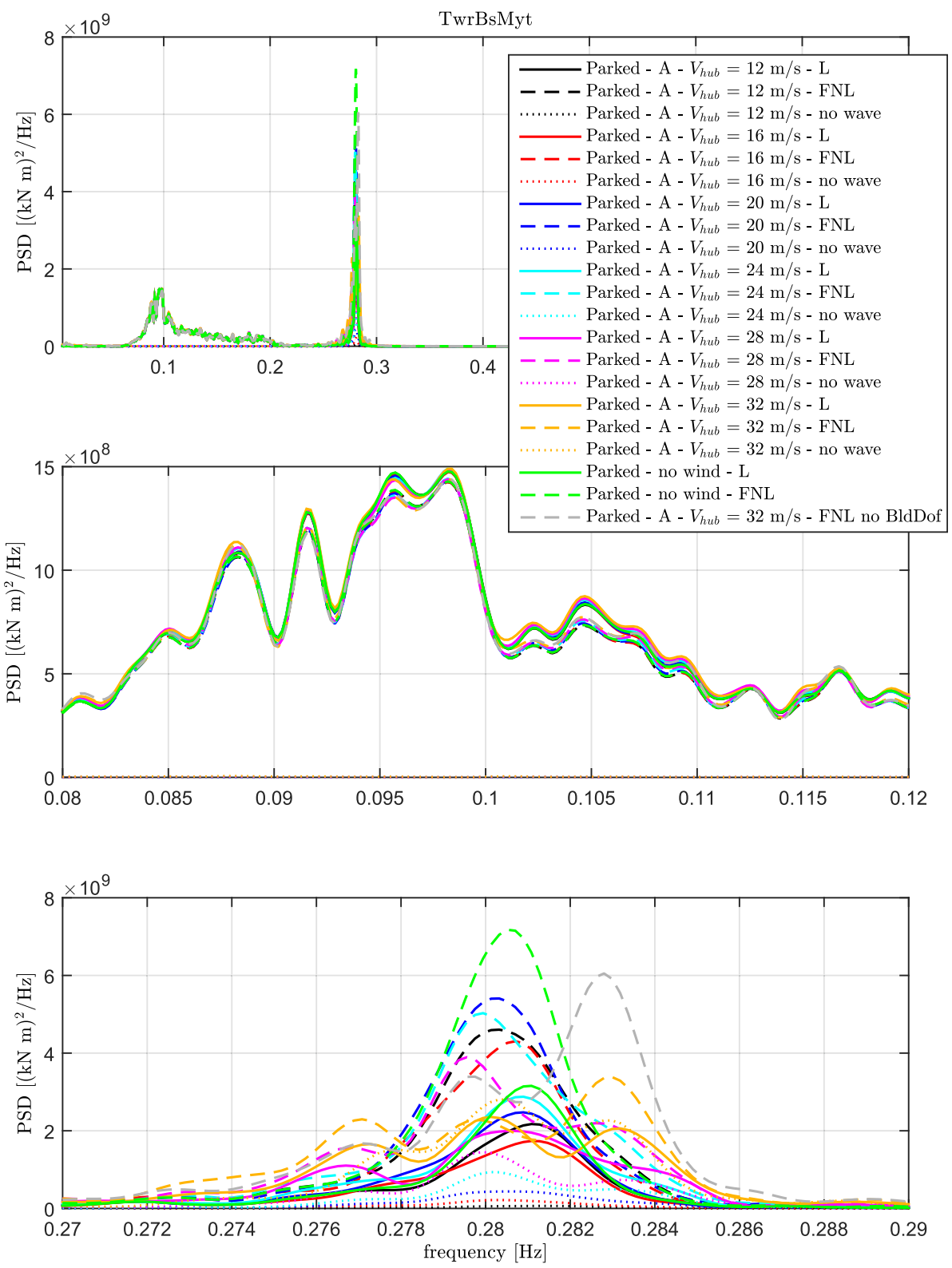

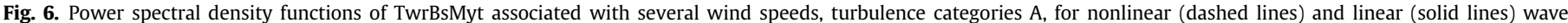
kinematics. The turbine is in a parked state.

Fig. 5, respectively), the wave influence is much greater than that due to the wind; finally, the rate of growth of these response statistics (s.d., max, DEL) is greater in the wind-only case than in the wind + wave case. This results from the larger hydrodynamic damping stemming from wave-structure interaction when waves are present.

\subsubsection{Response power spectral density functions}

The power spectral density (PSD) functions of the tower-base fore-aft bending moment is shown in Fig. 6. In the upper panel, the two dominant frequencies, namely, the wave frequency of about $0.09 \mathrm{~Hz}$ (wave peak spectral period, $T_{p}=10.82 \mathrm{~s}$ ) and the first tower fore-aft natural frequency of $0.28 \mathrm{~Hz}$ are clearly visible.

A close-up of the first spectral peak (middle panel of Fig. 6) shows no effect associated with turbulence intensity level and that the nonlinear wave kinematics modeling choice leads to a slightly lower energy at low frequencies, as expected.

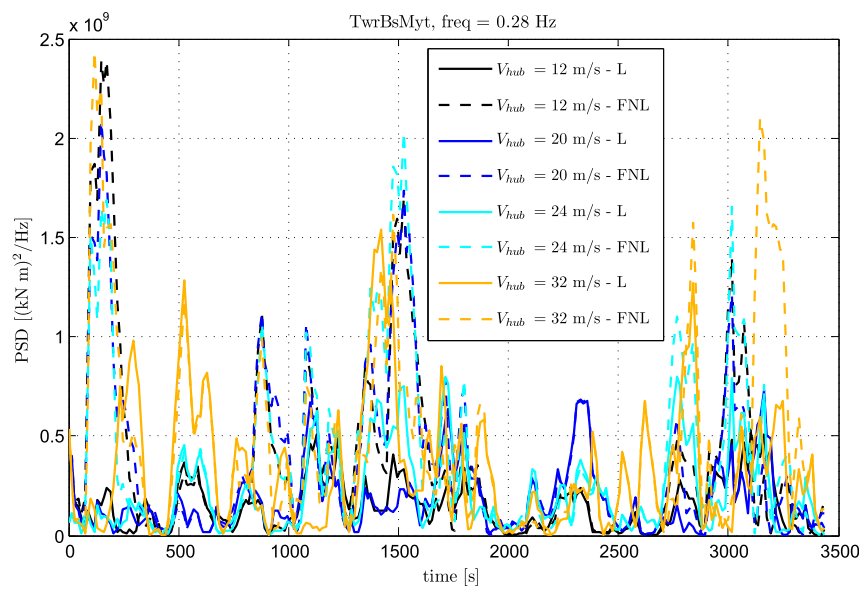

Fig. 7. Time series of TwrBsMyt PSD at $0.28 \mathrm{~Hz}$. The wind turbine is in a parked state. 

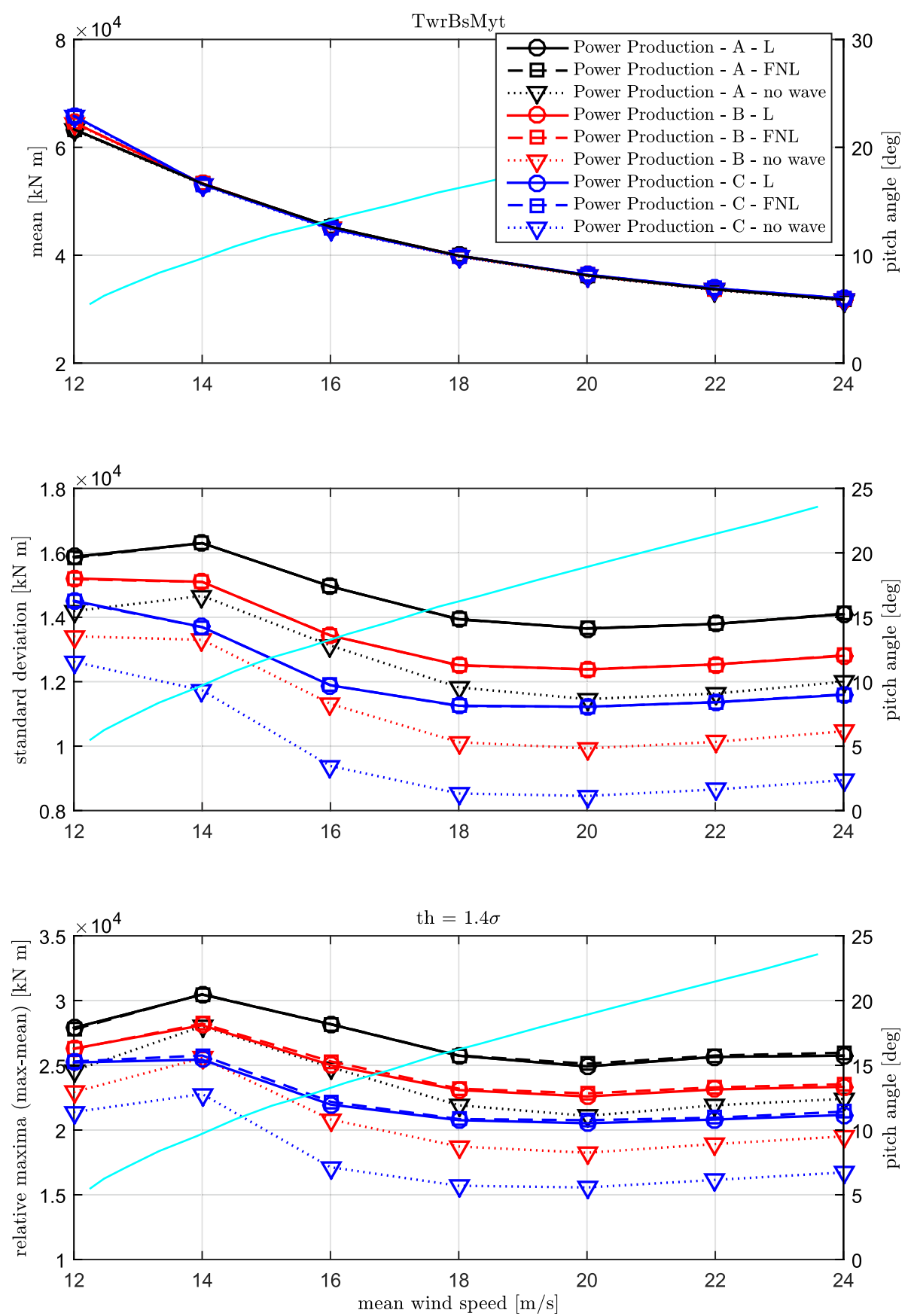

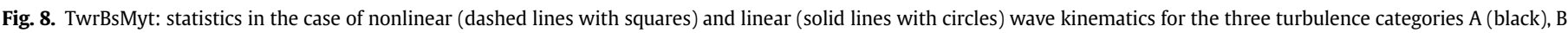

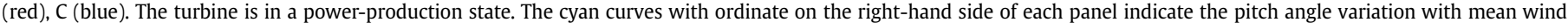
speed. (For interpretation of the references to colour in this figure legend, the reader is referred to the web version of this article.)

The response of the structure at the tower fundamental frequency (see bottom panel of Fig. 6) is quite sensitive to the wave modeling choice as well as to the mean wind speed. It is interesting to note that the maximum energy occurs around $0.28 \mathrm{~Hz}$ at an intermediate mean wind speed $(20 \mathrm{~m} / \mathrm{s})$, while at the highest wind speed $(32 \mathrm{~m} / \mathrm{s})$, the frequency content of the response is spread over a wider range of frequencies and reaches lower peaks (see orange dashed curve in Fig. 6). This appears to be counter-intuitive since, given the same sea conditions, the higher wind might be expected to lead to higher excitation. The justification of the behavior seen lies in the fact that the rotor blades, although parked with a collective pitch angle of $90^{\circ}$, experience some motion (under idling conditions) and some small vibrations. When the mean wind speed increases, the aeroelastic interactions become greater than at low wind speeds. The resulting increased damping associated with the rotor blade vibrations attenuates the PSD peak at $0.28 \mathrm{~Hz}$ for the higher wind speeds. To verify this assertion, consider the gray dashed curve in Fig. 6. It represents the PSD associated with a wind speed of $32 \mathrm{~m} / \mathrm{s}$, turbulence category A and with all the rotor blade DOFs suppressed - thus, the rotor effectively behaves like a rigid body attached to the tower top. The PSD shows that in the absence of vibrations of the blades, the aerodynamic damping is low so that 


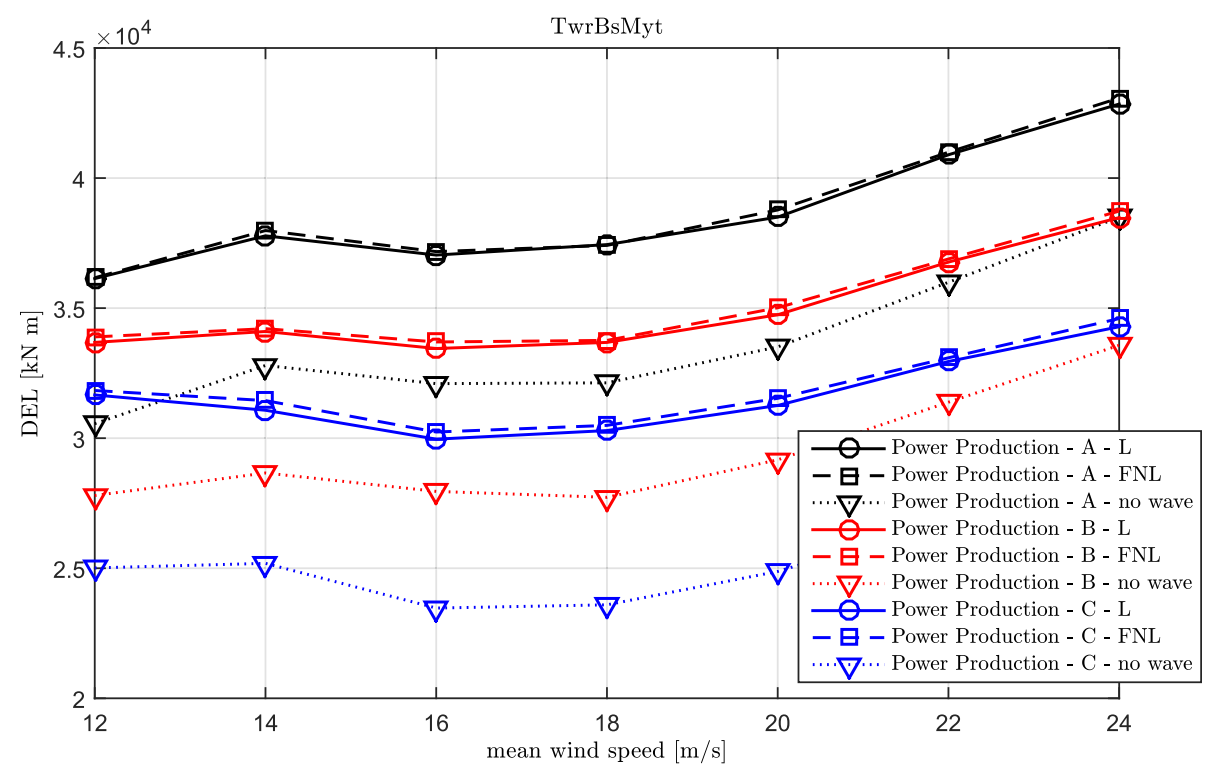

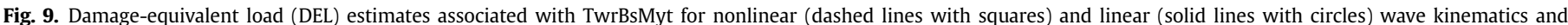

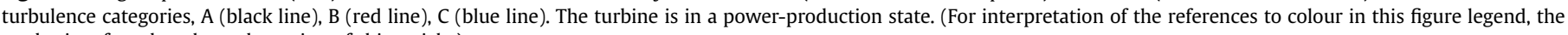
reader is referred to the web version of this article.)

the PSD peak at around $0.28 \mathrm{~Hz}$ is higher than in the case for the same wind speed and turbulence intensity but with flexible and idling blades (compare the orange and gray dashed curves in Fig. 6).

For wind speeds up to $24 \mathrm{~m} / \mathrm{s}$, wave action dominates; for higher winds, turbulence leads to excitation of more modes and a greater spread of the energy around $0.28 \mathrm{~Hz}$ is seen.

A key influence of aeroelastic interaction is easily understood by studying the PSDs (see the green dashed curves in the bottom panel of Fig. 6) associated with the reference base case consisting of waves alone. This admittedly unrealistic no-wind loading case has been added with a view to help better interpret the relative influences of the wind and nonlinear waves. In the absence of wind,

Table 1

Relevant properties of the wind turbine.

\begin{tabular}{ll}
\hline Power rating & $5 \mathrm{MW}$ \\
Rotor type & Upwind/3 blades \\
Rotor diameter & $126(\mathrm{~m})$ \\
Hub height & $90(\mathrm{~m})$ \\
Cut-in, rated, cut-out & $3,11.4,25(\mathrm{~m} / \mathrm{s})$ \\
Rated rotor speed & $12.1(\mathrm{rpm})$ \\
Rotor mass & $110,000(\mathrm{~kg})$ \\
Nacelle mass & $240,000(\mathrm{~kg})$ \\
Tower mass & $347,460(\mathrm{~kg})$ \\
\hline
\end{tabular}

Table 2

Comparison of DEL estimates for the TwrBsMyt response in parked and powerproduction turbine states (where \% Diff. equals $\left(\mathrm{DEL}_{\mathrm{FNL}}-\mathrm{DEL}_{\mathrm{L}}\right) / \mathrm{DEL}_{\mathrm{L}} \times 100$ ). Turbulence category A.

\begin{tabular}{lllllll}
\hline Turbine config. & Parked & & \multicolumn{4}{c}{ Power production } \\
\hline Wind speed & L & FNL & \% Diff. & L & FNL & \% Diff. \\
$12 \mathrm{~m} / \mathrm{s}$ & $2.058 \mathrm{e} 04$ & $2.412 \mathrm{e} 04$ & +17.2 & $3.614 \mathrm{e} 04$ & $3.617 \mathrm{e} 04$ & +0.1 \\
$14 \mathrm{~m} / \mathrm{s}$ & - & - & - & $3.778 \mathrm{e} 04$ & $3.798 \mathrm{e} 04$ & +0.5 \\
$16 \mathrm{~m} / \mathrm{s}$ & $2.069 \mathrm{e} 04$ & $2.388 \mathrm{e} 04$ & +15.4 & $3.704 \mathrm{e} 04$ & $3.717 \mathrm{e} 04$ & +0.4 \\
$18 \mathrm{~m} / \mathrm{s}$ & - & - & - & $3.744 \mathrm{e} 04$ & $3.741 \mathrm{e} 04$ & -0.1 \\
$20 \mathrm{~m} / \mathrm{s}$ & $2.113 \mathrm{e} 04$ & $2.441 \mathrm{e} 04$ & +15.5 & $3.850 \mathrm{e} 04$ & $3.877 \mathrm{e} 04$ & +0.7 \\
$22 \mathrm{~m} / \mathrm{s}$ & - & - & - & $4.090 \mathrm{e} 04$ & $4.099 \mathrm{e} 04$ & +0.2 \\
$24 \mathrm{~m} / \mathrm{s}$ & $2.163 \mathrm{e} 04$ & $2.466 \mathrm{e} 04$ & +14.0 & $4.285 \mathrm{e} 04$ & $4.308 \mathrm{e} 04$ & +0.5 \\
$28 \mathrm{~m} / \mathrm{s}$ & $2.227 \mathrm{e} 04$ & $2.511 \mathrm{e} 04$ & +12.8 & - & - & - \\
$32 \mathrm{~m} / \mathrm{s}$ & $2.381 \mathrm{e} 04$ & $2.603 \mathrm{e} 04$ & +9.3 & - & - & - \\
\hline
\end{tabular}

the aeroelastic interactions are minimized and the entire system experiences minimum damping. It is for this reason that the wave excitations produce their maximum effect on the overall structural response.

We discuss power spectra only for turbulence category A because very similar behavior is observed for the other turbulence categories.

Table 3

Comparison of DEL estimates for the TwrBsMyt response in parked and powerproduction turbine states (where \% Diff. equals $\left.\left(D^{2} L_{F N L}-D E L_{L}\right) / D E L_{L} \times 100\right)$. Turbulence category $\mathrm{B}$.

\begin{tabular}{lllllll}
\hline Turbine config. & Parked & & \multicolumn{5}{c}{ Power production } \\
\hline Wind speed & L & FNL & \% Diff. & L & FNL & $\%$ Diff. \\
$12 \mathrm{~m} / \mathrm{s}$ & $2.057 \mathrm{e} 04$ & $2.406 \mathrm{e} 04$ & +17.0 & $3.368 \mathrm{e} 04$ & $3.389 \mathrm{e} 04$ & +0.6 \\
$14 \mathrm{~m} / \mathrm{s}$ & - & - & - & $3.410 \mathrm{e} 04$ & $3.421 \mathrm{e} 04$ & +0.3 \\
$16 \mathrm{~m} / \mathrm{s}$ & $2.075 \mathrm{e} 04$ & $2.378 \mathrm{e} 04$ & +14.6 & $3.345 \mathrm{e} 04$ & $3.370 \mathrm{e} 04$ & +0.7 \\
$18 \mathrm{~m} / \mathrm{s}$ & - & - & - & $3.368 \mathrm{e} 04$ & $3.376 \mathrm{e} 04$ & +0.2 \\
$20 \mathrm{~m} / \mathrm{s}$ & $2.077 \mathrm{e} 04$ & $2.397 \mathrm{e} 04$ & +15.4 & $3.474 \mathrm{e} 04$ & $3.501 \mathrm{e} 04$ & +0.8 \\
$22 \mathrm{~m} / \mathrm{s}$ & - & - & - & $3.677 \mathrm{e} 04$ & $3.689 \mathrm{e} 04$ & +0.3 \\
$24 \mathrm{~m} / \mathrm{s}$ & $2.127 \mathrm{e} 04$ & $2.440 \mathrm{e} 04$ & +14.7 & $3.848 \mathrm{e} 04$ & $3.873 \mathrm{e} 04$ & +0.6 \\
$28 \mathrm{~m} / \mathrm{s}$ & $2.155 \mathrm{e} 04$ & $2.447 \mathrm{e} 04$ & +13.5 & - & - & - \\
$32 \mathrm{~m} / \mathrm{s}$ & $2.245 \mathrm{e} 04$ & $2.482 \mathrm{e} 04$ & +10.6 & - & - & - \\
\hline
\end{tabular}

Table 4

Comparison of DEL estimates for the TwrBsMyt response in parked and powerproduction turbine states (where \% Diff. equals $\left(D^{2} L_{F N L}-D E L_{L}\right) / D E L_{L} \times 100$ ). Turbulence category $\mathrm{C}$.

\begin{tabular}{lllllll}
\hline Turbine config. & Parked & & \multicolumn{4}{c}{ Power production } \\
\hline Wind speed & L & FNL & \% Diff. & L & FNL & $\%$ Diff. \\
$12 \mathrm{~m} / \mathrm{s}$ & $2.057 \mathrm{e} 04$ & $2.405 \mathrm{e} 04$ & +16.9 & $3.166 \mathrm{e} 04$ & $3.183 \mathrm{e} 04$ & +0.5 \\
$14 \mathrm{~m} / \mathrm{s}$ & - & - & - & $3.107 \mathrm{e} 04$ & $3.145 \mathrm{e} 04$ & +1.2 \\
$16 \mathrm{~m} / \mathrm{s}$ & $2.052 \mathrm{e} 04$ & $2.366 \mathrm{e} 04$ & +15.3 & $2.996 \mathrm{e} 04$ & $3.024 \mathrm{e} 04$ & +0.9 \\
$18 \mathrm{~m} / \mathrm{s}$ & - & - & - & $3.029 \mathrm{e} 04$ & $3.049 \mathrm{e} 04$ & +0.7 \\
$20 \mathrm{~m} / \mathrm{s}$ & $2.070 \mathrm{e} 04$ & $2.395 \mathrm{e} 04$ & +15.7 & $3.126 \mathrm{e} 04$ & $3.153 \mathrm{e} 04$ & +0.9 \\
$22 \mathrm{~m} / \mathrm{s}$ & - & - & - & $3.295 \mathrm{e} 04$ & $3.309 \mathrm{e} 04$ & +0.4 \\
$24 \mathrm{~m} / \mathrm{s}$ & $2.095 \mathrm{e} 04$ & $2.416 \mathrm{e} 04$ & +15.3 & $3.428 \mathrm{e} 04$ & $3.460 \mathrm{e} 04$ & +0.9 \\
$28 \mathrm{~m} / \mathrm{s}$ & $2.132 \mathrm{e} 04$ & $2.415 \mathrm{e} 04$ & +13.3 & - & - & - \\
$32 \mathrm{~m} / \mathrm{s}$ & $2.162 \mathrm{e} 04$ & $2.420 \mathrm{e} 04$ & +11.9 & - & - & - \\
\hline
\end{tabular}



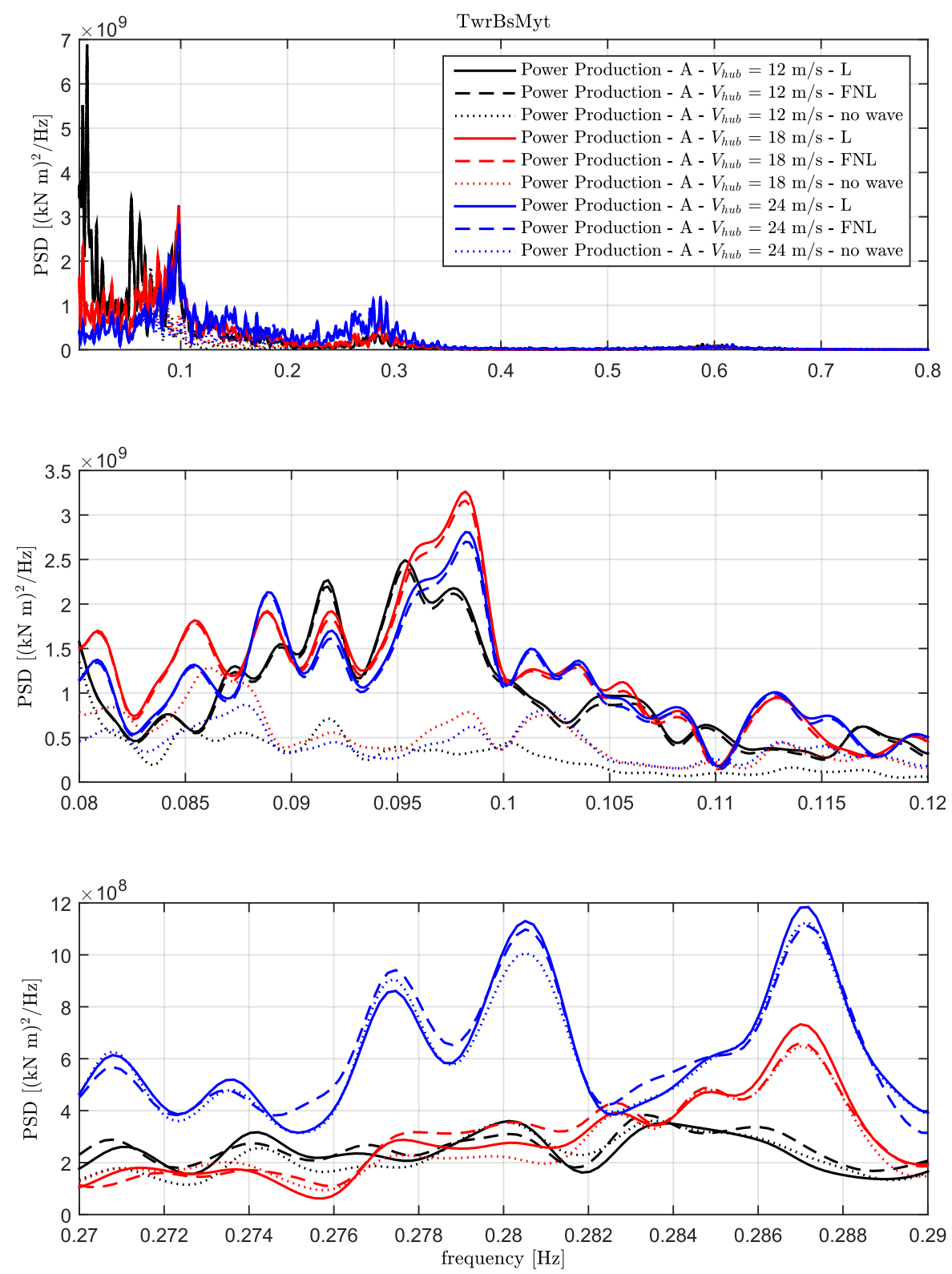

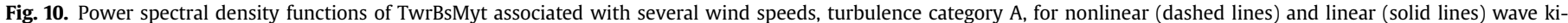
nematics. The turbine is in a power-production state.

An insight into the tower response around resonance is provided in Fig. 7, which shows, for selected mean wind speeds, the time-varying TwrBsMyt PSD ordinate at $0.28 \mathrm{~Hz}$ obtained by applying a moving window on the time series and computing the power spectra. The figure shows clearly that, whenever nonlinear waves are indicated (see Fig. 1), the tower bending moment levels are significantly greater for the FNL case compared with the L case, regardless of the mean wind speed.

\subsection{Power-production state}

We consider mean wind speeds from $12 \mathrm{~m} / \mathrm{s}$ to $24 \mathrm{~m} / \mathrm{s}$ in increments of $2 \mathrm{~m} / \mathrm{s}$. For each mean wind speed, three IEC turbulence categories - A, B, and C - are considered. The same linear $(\mathrm{L})$ and fully nonlinear (FNL) waves as for the parked state are considered for each wind condition. Thus, a total of 42 simulations are considered.

\subsubsection{Response statistics and fatigue loads}

Fig. 8 shows statistics of the tower-base fore-aft bending moment for the turbine in a power-production state. The mean TwrBsMyt (top panel of Fig. 8) decreases with increasing mean wind speed. This is due to the blade pitch control that reduces the overall wind thrust. The mean value of the tower bending moment is mainly influenced by the wind loading, while a change from $L$ to FNL wave kinematics has a negligible influence. Moreover, turbulence also does not affect the mean response as is confirmed by the similar mean response levels at the different turbulence categories (A, B and C), see top panel of Fig. 8.

The response standard deviation (s.d.) (middle panel of Fig. 8) suggests virtually no difference between the L and FNL wave kinematics models. This is due to the aeroelastic damping when the turbine is operating that dissipates the higher-order terms in the wave kinematics [6]. Concerning the effects of turbulence, the s.d. response is seen to increase when the turbulence intensity 
increases. At low pitch angles, corresponding to wind speeds between 12 and $14 \mathrm{~m} / \mathrm{s}$, higher turbulence levels tend to increase the s.d. response; whereas at higher wind speeds, larger pitch angles (10 deg and higher) are able to mitigate the effects of increasing turbulence and mean wind speed. For each turbulence category, the s.d. remains almost constant at the higher wind speeds up to $24 \mathrm{~m} / \mathrm{s}$.

While the blade pitch control is able to reduce the mean response at all wind speeds, for the extreme response we observe that the pitch control is effective for mean winds up to about $16 \mathrm{~m} /$ $\mathrm{s}$; above this level, no reduction of the extreme response results increasing the pitch angle beyond about $13 \mathrm{deg}$.

Fig. 9 shows damage-equivalent load (DEL) estimates for the turbine in a power-production state. For wind speeds in the range of $12-14 \mathrm{~m} / \mathrm{s}$, i.e., at low pitch angles, fatigue loads are influenced by the mean wind speed and turbulence level and would increase by greater amounts with no pitch control. At a wind speed of $14 \mathrm{~m} /$ $\mathrm{s}$, greater pitch angles of approximately $10 \mathrm{deg}$ are able to offset the influence of increasing wind speeds and mitigate fatigue loads such that lowest DEL levels occur for a wind speed of $16 \mathrm{~m} / \mathrm{s}$ (pitch angle of about $15 \mathrm{deg}$ ). Further increases in wind speed cannot be countered by the increase in pitch angle; hence, from $16 \mathrm{~m} / \mathrm{s}$ on, the increase in wind speed causes fatigue loads to grow at an almost constant rate with mean wind speed. DEL estimates with the nonlinear wave kinematics model are slightly higher (about 1\%) than those obtained with the linear wave kinematics.

Figs. 8 and 9 also show the no-waves case. We observe that waves have no effect on the mean response, whereas they induce an almost constant shift on the s.d., maximum response and DEL.

A comprehensive report of DEL estimates for different wind speeds, wave models, and turbine operating conditions is presented in Tables $2-4$, respectively, for turbulence categories, A, B, and $\mathrm{C}$.

\subsubsection{Response power spectral density functions}

The power spectral density (PSD) functions of the tower-base fore-aft bending moment for the power-production case is shown in Fig. 10. We discuss power spectra only for the turbulence category A because very similar behavior is observed for other turbulence categories. At higher winds, the response shows greater energy at the tower frequency of $0.28 \mathrm{~Hz}$ (see bottom panel of Fig. 10). This suggests greater sensitivity of the tower oscillations as the mean wind speed increases (see Fig. 9). Finally, we note that at both the dominant wave frequency and the tower fundamental frequency the nonlinear wave effects appear to be negligible.

The first tower bending mode, in the case of linear waves, is excited by the turbulent wind. This has been effectively verified by including the wind-only simulation case. In fact, it is seen in Fig. 10 that the peak at $0.28 \mathrm{~Hz}$ still occurs in the case with no waves. Fig. 10 emphasizes once more that in the power-production state, the contribution from waves is not significant.

\section{Conclusions}

In this study, the influence of selecting between linear and fully nonlinear wave kinematics models on the dynamic response of a bottom-supported wind turbine under different wind conditions has been investigated. The study was undertaken to help identify those environmental conditions that might require more accurate wave modeling in order to accurately assess structural performance and safety.

The main outcome of the study is that, when the turbine is parked, the consideration of fully nonlinear wave kinematics has a significant influence on both the maximum response and on the associated fatigue damage accumulation at all wind speeds.
Computations for nonlinear versus linear waves suggest an increase in response extreme values of about 15\% when going from linear to nonlinear waves, whereas damage-equivalent fatigue load increases ranged from $17 \%$ at low wind speeds to about $10 \%$ at high wind speeds. It is expected that, in long-term reliability studies, significant differences (over-predictions) in fatigue life can result if linear wave models are employed.

Because the differences in fatigue damage that result when one goes from a linear to a nonlinear wave model are different at low versus high wind speeds and because these fatigue load differences are greater at the more frequently observed lower wind speeds, it is reasonable to expect that the long-term fatigue reliability is influenced significantly as is the case with the long-term extreme loads.

In contrast, when the wind turbine is in a power-production state, the active control system plays a crucial role in limiting load levels that an increase of wind speed would otherwise cause. Accounting for nonlinear wave kinematics does not significantly affect extreme loads that are mainly driven by the wind. It is observed that a slight increase in damage-equivalent fatigue loads results with the nonlinear wave kinematics model and, at low wind speeds, as the turbulence intensity grows, the loads also increase. Beyond a mean wind speed of about $16 \mathrm{~m} / \mathrm{s}$, fatigue loads grow monotonically with mean wind speed. As shown in previous studies, when the turbine is a power-production state, the lower sensitivity to wave modeling is due to the higher levels of aerodynamic damping. However, it is important to note that the wind and waves are aligned in the present study. Lower damping levels may result when waves come from a different direction relative to the wind; then, wave kinematics modeling choices can be more important. Further studies on the role of nonlinear wave models in cases of different wind-wave misalignments need to be considered in the future.

\section{References}

[1] E. Marino, C. Lugni, C. Borri, A novel numerical strategy for the simulation of irregular nonlinear waves and their effects on the dynamic response of offshore wind turbines, Comput. Methods Appl. Mech. Eng. 255 (2013) 275-288.

[2] B.T. Paulsen, H. Bredmose, H.B. Bingham, An efficient domain decomposition strategy for wave loads on surface piercing circular cylinders, Coast. Eng. 86 (2014) 57-76.

[3] E. Marino, C. Borri, U. Peil, A fully nonlinear wave model to account for breaking wave impact loads on offshore wind turbines, J. Wind Eng. Ind. Aerodyn. 99 (4) (2011) 483-490.

[4] E. Marino, C. Borri, C. Lugni, Influence of wind-waves energy transfer on the impulsive hydrodynamic loads acting on offshore wind turbines, J. Wind Eng. Ind. Aerodyn. 99 (6-7) (2011) 767-775.

[5] E. Marino, C. Borri, C. Lugni, Extreme response of offshore wind turbines due to fully nonlinear waves, in: Proc. 8th Int. Conf. Struct. Dyn. EURODYN 2011 2011, pp. 3443-3449.

[6] E. Marino, C. Lugni, C. Borri, The role of the nonlinear wave kinematics on the global responses of an OWT in parked and operating conditions, J. Wind Eng. Ind. Aerodyn. 123 (2013) 363-376.

[7] E. Marino, H. Nguyen, C. Lugni, L. Manuel, C. Borri, Irregular nonlinear wave simulation and associated loads on offshore wind turbines, J. Offshore Mech. Arct. Eng. 137 (2) (2014) 021901.

[8] E. Marino, C. Lugni, C. Borri, Aero-hydroelastic instabilities on an offshore fixed-bottom wind turbine in severe sea state, in: Proc. 11th Int. Conf. Hydrodyn. (ICHD 2014) Oct. 19 24, 2014, No. Ichd, ICHD 2014, 2014, pp. 1-8.

[9] J.R. Chaplin, R.C.T. Rainey, R.W. Yemm, Ringing of a vertical cylinder in waves, J. Fluid Mech. (1997) 119-147.

[10] J. Grue, M. Huseby, Higher-harmonic wave forces and ringing of vertical cylinders, Appl. Ocean. Res. 24 (4) (2002) 203-214. ISSN 0141-1187.

[11] B.T. Paulsen, H. Bredmose, H. Bingham, N. Jacobsen, Forcing of a bottommounted circular cylinder by steep regular water waves at finite depth, J. Fluid Mech. 755 (2014) 1-34.

[12] P. Agarwal, L. Manuel, Incorporating irregular nonlinear waves in coupled simulation and reliability studies of offshore wind turbines, Appl. Ocean. Res. 33 (3) (2011) 215-227.

[13] A. Natarajan, Influence of second-order random wave kinematics on the design loads of offshore wind turbine support structures, Renew. Energy 68 (2014) 829-841. 
[14] E. Marino, G. Stabile, C. Borri, C. Lugni, A comparative study about the effects of linear, weakly and fully nonlinear wave models on the dynamic response of offshore wind turbines, in: A. Zingoni (Ed.), Res. Appl. Struct. Eng. Mech. Comput. SEMC 2013, Taylor and Francis Group, London, UK CRC Press, Cape Town, 2013.

[15] E. Marino, C. Lugni, G. Stabile, C. Borri, Coupled dynamic simulations of offshore wind turbines using linear, weakly and fully nonlinear wave models : the limitations of the second-order wave theory, in: 9th Int. Conf. Struct. Dyn. (EURODYN 2014), 2014.

[16] E. Marino, C. Lugni, L. Manuel, H. Nguyen, C. Borri, Simulation of nonlinear waves on offshore wind turbines and associated fatigue load assessment, in: 33nd Int. Conf. Ocean. Offshore Arct. Eng., 2014, pp. 1-9.

[17] H.F. Veldkamp, J. van der Tempel, Influence of wave modelling on the prediction of fatigue for offshore wind turbines, Wind Energy 8 (1) (2005) 49-65.

[18] M.B. Van Der Meulen, T. Ashuri, G.J.W. Van Bussel, D.P. Molenaar, Influence of nonlinear irregular waves on the fatigue loads of an offshore wind turbine, in: Sci. Mak. Torque from Wind. 4th Sci. Conf. Oldenbg. (Germany), 9-12 Oct, 2012, 2012.

[19] P. Agarwal, L. Manuel, On the modeling of nonlinear waves for prediction of long-term offshore wind turbine loads, J. Offshore Mech. Arct. Eng. 131 (4) (2009) 41601

[20] E. Marino, H. Nguyen, C. Lugni, L. Manuel, C. Borri, Irregular nonlinear wave simulation and associated loads on offshore wind turbines, in: $32 \mathrm{nd}$ Int Conf. Ocean. Offshore Arct. Eng., No. M, ASME Digital Library NOOPisbn: 978-0 7918-5542-3, 2013 pp. V008T09A066-.

[21] P. Ragan, L. Manuel, Comparing estimates of wind turbine fatigue loads using time-domain and spectral methods, Wind Eng.. 31(2).

[22] B. Yeter, Y. Garbatov, C. Guedes Soares, Fatigue damage assessment of fixed offshore wind turbine tripod support structures, Eng. Struct. 101 (2015) $518-528$.

[23] B. Yeter, Y. Garbatov, C. Guedes Soares, Evaluation of fatigue damage model predictions for fixed offshore wind turbine support structures, Int. J. Fatigue 87 (2016) 71-80.

[24] L.E.S. Stieng, R. Hetland, S. Schafhirt, M. Muskulus, Relative assessment of fatigue loads for offshore wind turbine support structures, Energy Procedia 80 (2015) 229-236.

[25] W. Dong, T. Moan, Z. Gao, Long-term fatigue analysis of multi-planar tubular joints for jacket-type offshore wind turbine in time domain, Eng. Struct. 33 (6) (2011) 2002-2014.

[26] J.D. Sørensen, Reliability-based calibration of fatigue safety factors for offshore wind turbines, Int. J. Offshore Polar Eng. 22 (3) (2012) 234-241.

[27] W. Dong, T. Moan, Z. Gao, Fatigue reliability analysis of the jacket support structure for offshore wind turbine considering the effect of corrosion and inspection, Reliab. Eng. Syst. Saf. 106 (2012) 11-27.

[28] S. Kelma, P. Schaumann, Probabilistic fatigue analysis of jacket support structures for offshore wind turbines exemplified on tubular joints, Energy
Procedia 80 (2015) 151-158.

[29] P. Passon, Damage equivalent windwave correlations on basis of damage contour lines for the fatigue design of offshore wind turbines, Renew. Energy 81 (2015) 723-736.

[30] J. Jia, Wind and structural modelling for an accurate fatigue life assessment of tubular structures, Eng. Struct. 33 (2) (2011) 477-491.

[31] L. Ziegler, S. Voormeeren, S. Schafhirt, M. Muskulus, Sensitivity of wave fatigue loads on offshore wind turbines under varying site conditions, Energy Procedia 80 (2015) 193-200.

[32] L. Ziegler, S. Voormeeren, S. Schafhirt, M. Muskulus, Design clustering of offshore wind turbines using probabilistic fatigue load estimation, Renew. Energy 91 (2016) 425-433.

[33] M.C. Holtslag, W.A.A.M. Bierbooms, G.J.W. van Bussel, Wind turbine fatigue loads as a function of atmospheric conditions offshore, Wind Energy 19 (2016) 1917-1932, http://dx.doi.org/10.1002/we.1959.

[34] F.P. Brennan, A framework for variable amplitude corrosion fatigue materials tests for offshore wind steel support structures, Fatigue Fract. Eng. Mater. Struct. 37 (7) (2014) 717-721.

[35] O. Adedipe, F. Brennan, A. Kolios, Corrosion fatigue load frequency sensitivity analysis, Mar. Struct. 42 (2015) 115-136.

[36] S. Schløer, H. Bredmose, H.B. Bingham, T.J. Larsen, Effects from fully nonlinear irregular wave forcing on the fatigue life of an offshore wind turbine and its monopile foundation, in: Ocean Sp. Util. Ocean Renew. Energy, ASME, Schloer2012, vol. 7, 2012, p. 393.

[37] J.M. Jonkman, L.B.J. Marshall, FAST User's Guide, Tech. rep., Technical Report NREL/EL-500-38230, 2005

[38] B.J. Jonkman, L. Kilcher, TurbSim User's Guide, Tech. Rep. September, Technical Report NREL/TP Version 1.06.00, 2012.

[39] IEC 61400-1 Wind turbines - Part 1: Design requirements 3rd ed.

[40] C. Sim, S. Basu, L. Manuel, On space-time resolution of inflow representations for wind turbine loads analysis, Energies 5 (12) (2012) 2071-2092.

[41] D.J. Laino, A. Craig Hansen, AeroDyn User's Guide, Tech. Rep., National Renewable Energy Laboratory, 2002.

[42] P. J. Moriarty, A. C. Hansen, AeroDyn Theory Manual AeroDyn Theory Manual (December).

[43] J.R. Morison, J.W. Johnson, S.A. Schaaf, The force exerted by surface waves on piles, J. Pet. Technol. 2 (05) (1950) 149-154.

[44] K.E. Mittendorf, Joint description methods of wind and waves for the design of offshore wind turbines, Mar. Technol. Soc. J. 43 (3) (2009) 23-33.

[45] J. Jonkman, S. Butterfield, W. Musial, G. Scott, Definition of a 5-MW Reference Wind Turbine for Offshore System Development, Tech. Rep. February, 2009.

[46] E. Bush, L. Manuel, Foundation models for offshore wind turbines, in: 47th AIAA Aerosp. Sci. Meet. Incl. New Horizons Forum Aerosp. Expo., Aerospace Sciences Meetings, American Institute of Aeronautics and Astronautics, 2009.

[47] E.A. Rendon, L. Manuel, Long-term loads for a monopile-supported offshore wind turbine, Wind Energy 17 (2) (2014) 209-223. 